\title{
Changes in the characteristics of families with Down's syndrome children
}

\author{
BILLIE SHEPPERDSON \\ From the Institute of Health Care Studies, University College of Swansea, Singleton Park, Swansea SA2 8PP
}

SUMMARY A study of two cohorts of Down's syndrome children living at home in South Wales and born in 1964-66 and 1973-75 respectively shows that there are significant differences in the characteristics of their families. Parents of those born in the seventies were younger at the birth and of higher social class than parents with children born in the sixties. In the seventies the Down's syndrome child was more likely to be the couple's first child. Most changes result from the introduction of the amniocentesis test which is offered to older pregnant women. It is suggested that the social class differences are likely to be explained by changes in fertility in the various social classes.

Down's syndrome (DS) is not a condition which is spread evenly across the population. Apart from the increased risk for those who carry the rare, inherited form of the condition, there are other variations in incidence. It is well known that older mothers are more likely than others to have a DS baby, but how far there is an increased risk for older fathers is more controversial. ${ }^{1-3}$ Variations in incidence have also been found in different places and years. ${ }^{45}$ The role of exposure to radiation, through personal $x$ rays or through background radiation, in increasing the risk of producing a DS child is uncertain. ${ }^{1}$ It is suggested that the incidence of DS may be increasing. ${ }^{23}$

There are also factors that affect the prevalence of DS. The life expectancy for DS individuals has improved over the years. DS children are still more vulnerable than others, ${ }^{6}$ and Elwood ${ }^{7}$ found that in Northern Ireland DS babies born to mothers over 35 years old had a higher mortality rate than those born to younger mothers. The most significant recent development affecting prevalence, however, has been the introduction of the amniocentesis test which allows a DS fetus to be detected and aborted if the parents wish it. The test became available in the UK in the early seventies. Since this test carries a small risk of spontaneous abortion, the test was routinely offered only to women over 40 years at first, although in some areas it is now offered to women over 37 years old.

Juberg $^{8}$ points out that efforts to understand genetic mechanisms are made in order to make predictions about individuals and, ideally, to permit us to 'recognise in whom, at what time, and in which circumstances' abnormalities will occur. This, of course, is most important, but simply identifying common characteristics of families is a legitimate interest for those who are planning services for disabled individuals. The introduction of the amniocentesis test means that it is possible to predict that there will have been changes in the characteristics of families with DS children. Since fewer older mothers are likely to be giving birth to DS children it is probable that families with a DS child will, nowadays, more nearly resemble the composition and age structure of families with only normal children. These changes have implications for the DS child and his upbringing and also for the services which need to be provided for his care.

\section{Method}

A study of all DS children, born from 1964 to 1966 and living at home in South Wales, was made in 1972. A further study of these children was made in 1981 when the children were in their mid-teens. There were 27 girls and 29 boys in the study. Three mothers refused to cooperate, and the children could not be included in the study. Children were tested on language and social competence, and carers were interviewed.

In addition, in 1981, a study was made of all DS children living at home in South Wales who were born in 1973-1975. There were 14 girls and 12 boys in the study. Again, three children could not be included, one because the mother did not wish to be interviewed, and two because the geographical 
boundary of the study was changed slightly. Their inclusion would not have affected the argument presented. Children were again tested and carers interviewed.

In both 1981 studies particular care was taken to include all DS chidlren living at home in South Wales and born in the study years.

A comparison of the family circumstances of the two cohorts, when they were at similar ages, was then possible. The study is of children living at home and therefore provides important information for those planning domiciliary services.

\section{Results}

AGE OF PARENTS AT BIRTH

Mothers who had their DS babies in 1973-1975 were younger at the birth of their children than those who had given birth 9 years earlier, in 1964-66-an average of 29.8 years compared with 33.5 years. Fathers, too, followed this pattern and their average ages at the birth of their children was 32.0 years for the $70 \mathrm{~s}$ group and 36.5 years for the teenagers' fathers. Among the mothers, not unexpectedly, there were significantly fewer mothers giving birth over the age of 40 years. Only $3(12 \%)$ of those mothers giving birth in the 70 s were over 40 years compared with 26 $(49 \%)$ of mothers who had their babies in the $60 \mathrm{~s}$ $\left(\chi^{2}=9.015 ;\right.$ d.f. $\left.=1 ; \mathrm{p}<0.01\right)$.

\section{SIZE OF FAMILY}

The 1964-1966 cohort tended to come from larger families than the 1973-1975 cohort but these differences did not reach significance. Table 1 shows the position of the 1964-1966 cohort in 1972-that is the age at which they could be compared with the 1973-1975 cohort in 1981. Six normal children were born subsequently to the parents of the older cohort-although two of these six were to the child's father and another woman. In 1972 the average family size for those born in 1964-66 was $3 \cdot 4$ children compared with 2.7 in 1981 for those born in 1973-5.

Table 1 Family sizes for the two cohorts at similar ages (1972 and 1981) (\% in brackets)

\begin{tabular}{|c|c|c|}
\hline \multirow[b]{2}{*}{ Number of children } & \multicolumn{2}{|c|}{ Year of birth } \\
\hline & $1964-66$ & $1973-75$ \\
\hline $\begin{array}{l}1 \\
2 \\
3 \\
4 \\
5 \\
6 \\
6 \\
7 \\
8\end{array}$ & $\begin{array}{rr}4 & (7) \\
13 & (24) \\
20 & 36) \\
7 & (13) \\
5 & (9) \\
3 & 6 \\
2 & 4 \\
1 & (2)\end{array}$ & $\begin{array}{rr}2 & (8) \\
12 & (46) \\
9 & (35) \\
1 & (4) \\
1 & -(4) \\
1 & (4)\end{array}$ \\
\hline Totals & $55^{*}$ & 26 \\
\hline
\end{tabular}

*One not available.
POSITION IN FAMILY

While only a fifth of the children born in 1964-66 were the first born in a family, half of those born in the seventies were the first child (table 2 ). Not only this but the age difference between the youngest child and his nearest sibling had decreased from 6.3 years on average in 1972 to 4.6 years for the 1973-75 cohort in 1981 (excluding one exceptional case of 24 years difference.)

\section{MARITAL STATUS}

There were few differences in the marital status of the two sets of parents in 1972 and 1981 . There were slightly higher percentages of widowed, separated and divorced mothers in the older group. In 1972 there were three instances of obvious rejection of the new baby by the father and subsequent divorces. There were no reported instances of divorce for this reason in the younger group.

SOCIAL CLASS OF PARENTS

The finding that the children born in 1973-1975 had younger parents, came from smaller families, and were more often the eldest child in a family than those born nine years earlier is not wholly surprising if it is expected that nowadays older women, because of amniocentesis and abortion, are less likely to be having DS babies. A more unexpected difference between the cohorts was the social class composition. Table 3 shows that in the younger cohort $46 \%$ were in social classes I and II compared with only $23 \%$ of the 1964-66 cohort, and $22 \%$ of the population in the 1971 census.

Table 2 Position of child in family (\% in brackets)

\begin{tabular}{lccc}
\hline & \multicolumn{2}{l}{ Year of birth } & \\
\cline { 2 - 3 } & $1964-66$ & $1973-75$ & Total \\
\hline Only child & $4(7)$ & $2(8)$ & 6 \\
Eldest child & $7(13)$ & $11(42)$ & 18 \\
Middle child & $10(18)$ & $12(4)$ & 11 \\
Youngest child & $35(63)$ & $12(46)$ & 47 \\
Totals & 56 & 26 & 82 \\
\hline
\end{tabular}

Only and eldest children compared with middle and youngest children: $x^{2}=6.51 ; \mathrm{df}=1 ; p<0.02$.

Table 3 Social class composition of cohorts by fathers' occupations ( $\%$ in brackets)

\begin{tabular}{|c|c|c|c|c|}
\hline Social classes & $1964-66$ & $\begin{array}{l}\text { Social class } \\
\text { Wales, } 1966\end{array}$ & $1973-75$ & $\begin{array}{l}\text { Social class } \\
\text { Wales, } 1971\end{array}$ \\
\hline $\begin{array}{l}\text { I and II } \\
\text { III } \\
\text { IV and V }\end{array}$ & $\begin{array}{l}13(23) \\
30(54) \\
13(23)\end{array}$ & $\begin{array}{l}(20) \\
46) \\
(35)\end{array}$ & $\begin{array}{r}12(46) \\
11(42) \\
3(12)\end{array}$ & $\left\{\begin{array}{l}22) \\
48 \\
30)\end{array}\right.$ \\
\hline Totals & 56 & & 26 & \\
\hline
\end{tabular}

Difference between proportions, $z=2.099 ; p<0.05$. 
Whether or not DS children are over represented among higher social classes has been discussed by others. Carr ${ }^{9}$ reported the anecdotal evidence of Giannini and Goodman that this is so, but she concluded that the biased social class composition of her own sample had been drawn by chance. Table 4 shows the social class composition of Carr's own 1964 London and Surrey sample and Gath's 1970-71 Oxford sample. ${ }^{1011}$

Taking the five series of data presented in tables 3 and 4 a comparison of each of the observed numbers of DS children by social class with the expected number, based on the population statistics, generates an overall $\chi^{2}$ figure of 21.4 which, with 10 degrees of freedom, is significant at the $2 \%$ level. This indicates that, over a range of different UK samples, there exists a significant association between social class and families with DS children. With the exception of the Camberwell series, all figures show the same association, ie, a higher observed than expected number of DS children in the higher social classes.

The OPCS Monitor 'Congenital malformations and parents' occupations ' ${ }^{12}$ reports higher rates of DS children born to schoolteachers' wives and suggests that this may be explained by such parents having children at older than average ages. A Canadian study has suggested that DS births should be monitored for trends in incidence in order to investigate possible correlations with parental occupation and geographical area. ${ }^{13}$

The cause of the social class differences between the 1964-66 and 1973-75 cohorts remains something of a mystery. Small numbers, of course, are always vulnerable to atypical findings which have occurred simply by chance.

Alternatively, it may be that the change in social class composition has occurred through differential deaths of children from birth. Normal children of low social class parents are more likely to die than others, and it may be that DS children, with their inherent vulnerability, are even more susceptible and have died in sufficient numbers to have altered the sample. There is little ready explanation, however, of why this should have occurred in the early 70 s but not in the early $60 \mathrm{~s}$.

A further factor to be considered is rejection of the child, resulting in children being brought up away from their natural parents. In the sixties there was little choice for parents-few were given any options on child care and the few institutional places that were then available were often considered unacceptable by parents. By the seventies fostering and even adoption was more common and so children could have been lost from the population because of this phenomenon. All the evidence on rejection of DS children, however, suggests that it is those in higher social classes who are more likely to reject their mentally retarded children, and so it is probable that most losses from this cause would be to those in higher social classes rather than to those in the lower? social classes.

It has been suggested that women in higher socialo classes have babies at older ages. Table 5 shows the average ages of mothers at the birth of their DS babies.

Another influence is the difference in fertility between the social classes. There has been a decline in births in all social classes since 1964 , but the most rapid decline has taken place in the lowest social classes, and this has resulted in changes in the proportions of births to the various social classes (see table 6). These changes are not sufficiently great to explain the over representation of high social class DS children in the 1973-5 cohort.

Table 4 Social class composition of DS children in other studies (\% in brackets)

\begin{tabular}{|c|c|c|c|c|c|c|}
\hline Social classes & $\begin{array}{l}\text { Carr } \\
\text { London \& Surrey } \\
\text { DS binths, } 1964\end{array}$ & $\begin{array}{l}\text { London \& Surrey } \\
\text { Population } \\
1961 / 66\end{array}$ & $\begin{array}{l}\text { Gath } \\
\text { Oxford } \\
\text { DS births 1970-71 }\end{array}$ & $\begin{array}{l}\text { South East } \\
\text { Population } \\
\text { Census, } 1971\end{array}$ & $\begin{array}{l}\text { Camberwell Register } \\
\text { (from Carr) } \\
\text { DS births, } 1971\end{array}$ & $\begin{array}{l}\text { Camberwell } \\
\text { Population } \\
1961\end{array}$ \\
\hline $\begin{array}{l}\text { I and II } \\
\text { III } \\
\text { IV and V }\end{array}$ & $\begin{array}{l}16(37) \\
17\left(\begin{array}{l}40 \\
10\end{array}\right)\end{array}$ & $\left\{\begin{array}{l}28) \\
49 \\
23\end{array}\right)$ & $\begin{array}{r}14(47) \\
11 \\
5\end{array}\left(\begin{array}{l}377 \\
17\end{array}\right)$ & $\left(\begin{array}{l}29) \\
48 \\
23\end{array}\right)$ & $\begin{array}{rr}4 & (9) \\
24 & (53) \\
17 & (38)\end{array}$ & $\left(\begin{array}{l}10) \\
60) \\
30)\end{array}\right.$ \\
\hline Totals & 43 & & 30 & & 45 & \\
\hline
\end{tabular}

Table 5 Average age of mothers at birth of DS child

\begin{tabular}{llll}
\hline Social classes & Births $1964-66$ & Average age of mothers at birth & Births 1973-75 \\
\hline I and II & $\mathrm{n}=12$ & $33 \cdot 8$ & $\mathrm{n}=12$ \\
III & $\mathrm{n}=29$ & $32 \cdot 7$ & $\mathrm{n}=11$ \\
IV and V & $\mathrm{n}=12$ & $35 \cdot 4$ & $\mathrm{n}=3$ \\
Totals & $\mathrm{n}=53^{*}$ & $33 \cdot 5$ & $\mathrm{n}=26$ \\
\hline
\end{tabular}

England and Wales mean age of women at childbirth 1966-26.8 years.

England and Wales mean age of women at childbirth 1975-26.3 years.

*Three maternal ages not available. 
Table 6 Changes in proportions of births to different social classes

\begin{tabular}{|c|c|c|c|c|}
\hline \multirow[b]{2}{*}{ Social classes } & \multicolumn{2}{|c|}{ Percentages of UK births ${ }^{14}$} & \multirow{2}{*}{$\begin{array}{l}\text { Percentages of DS children in } S \text {. Wales } \\
1964-66\end{array}$} & \multirow{2}{*}{$\begin{array}{l}\text { Percentages of DS children in } S \text {. Wales } \\
1973-75\end{array}$} \\
\hline & 1970 & 1975 & & \\
\hline $\begin{array}{l}\text { I and II } \\
\text { III } \\
\text { IV and V } \\
\text { Other }\end{array}$ & $\begin{array}{r}21 \\
52 \\
23 \\
4\end{array}$ & $\begin{array}{r}26 \\
49 \\
20 \\
5\end{array}$ & $\begin{array}{l}23 \\
54 \\
23 \\
-\end{array}$ & $\begin{array}{l}46 \\
42 \\
12 \\
-\end{array}$ \\
\hline
\end{tabular}

A tentative explanation for these differences, based on a combination of social rather than environmental factors, is as follows. Dunnell ${ }^{15}$ suggests that in "the early stages of family formation the gap between the social classes has widened" and it may be this widening gap which has affected the numbers of DS births in the various social classes. There are two influences at work, one affecting the higher, and one affecting the lower, social classes.

For those in social classes I and II, later marriage and a longer interval between marriage and the birth of the first child means that mothers are older when they begin childbearing and consequently more at risk of having a DS child. The notable underrepresentation of social classes IV and V mothers in the 1973-1975 cohort may perhaps be explained by the earlier marriage and narrower interval between marriage and childbirth of these women. It has been said that the most rapid decline in fertility is to those in lower social classes, and Dunnell $^{15}$ reports little difference in family sizes between social classes I and II; III; and IV and V $(2 \cdot 0 ; 2 \cdot 1 ; 2 \cdot 3$ children respectively) after 10 years of marriage. Families with over four children are increasingly a rarity. It seems likely that it is increasingly unusual for women in social classes IV and $\mathrm{V}$ to go on producing children at older (and riskier from the DS point of view) ages. Consequently, there are fewer women in social classes IV and V than expected having DS children. It is worth noting that two of the three mothers in social classes IV and V in the 1973-1975 cohort were over 40 years at the birth of their DS children and should have been offered amniocentesis given adequate antenatal care. From the information given in their interviews, it seems probable that both would have opted for abortion. The only other woman over 40 years at the birth lived abroad when her DS child was born.

\section{Discussion}

It is intriguing to speculate on the reasons for these changes but such considerations should not lead us to overlook the fact that the needs of DS children are consequently changing. Changes in the characteristics of families with DS children have implications for the families and the DS children themselves, as well as for the types of services that need to be provided to help.

Before amniocentesis was available for screening older pregnant women, at least half of families with a DS child were atypical. Parents were older than average, the DS child was often the youngest member of the family, and siblings often were too old to be real companions to them. Nowadays, families are more likely to follow the normal pattern, and this will reduce the differences that may exist between them and those families which have only normal children. In addition, the DS child himself is more likely to encounter the rough and tumble of family life with siblings nearer his own age. Through his siblings he will be more likely to be included in the neighbourhood peer group although there is little evidence from other data in this study that this means of introduction makes any substantial and positive difference to his circle of friends when the DS child reaches his teens.

It is likely that younger parents will have a different approach to the upbringing of their DS child. In 1972 mothers over 40 were significantly more likely to be lenient and "baby" their children. Seventy two per cent of the over 40s, for instance, still had the DS child in their own bedroom at night. In both 1972 and 1981 most parents felt that over indulgence was not in the best interests of the child, and parents with the youth and energy to carry a firm policy through and with other young children to militate against any "favourites" or "babying", may encourage the DS child to increased maturity.

The high social class background of the younger children is a further point in their favour. Normal children tend to have higher achievements if they have been brought up in middle class homes, and DS children seem to respond to the same influences. ${ }^{16}$ However, the social class composition of the younger population means that overall improvements in the achievements of young DS children must be viewed with caution: advances may result from the younger children's relatively advantaged home background and not simply from improvements in services. In fact the relationship between the two factors is probably synergistic.

Turning to the implications for services, since parents in the seventies are younger than those who gave birth in the sixties, it is likely that fewer 
teenagers and young adults will require full time care since parents who have brought their children up are usually willing to keep the young handicapped adults at home if their own health permits it. On the other hand, it can be predicted that parents in higher social classes will have higher expectations about the quantity and quality of services and will make a more effective pressure group. In particular, they are likely vigorously to press for any changes that accelerate the move towards "normalisation" for DS people. While in the sixties the view that institutional care was an acceptable form of care for mentally handicapped people was replaced by a move towards family care, the emphasis has now shifted again towards integration and providing care within the community. Consequently, while new services in the seventies concentrated on helping families to cope, (eg Attendance Allowance, Family Fund, home teaching schemes), efforts now centre on providing opportunities for mentally handicapped people themselves to have access to normal patterns of education, housing, work, and leisure.

I am grateful to the families and children who took part in the study and to The Joseph Rowntree Memorial Trust who funded it. Thanks are also due to colleagues Dr WR Bytheway and Mrs J Cleary.

\section{References}

${ }^{1}$ Sankaranarayanan $\mathrm{K}$. The role of non disjunction in aneuploidy in man: An overview. Mutation Research 1979; 61: 1-28.
${ }^{2}$ Baraitser M. Down's syndrome. Hospital Update October $1980 ; 1021-6$.

${ }^{3}$ Abrams KI, Bennett JW. Current findings in Down's Syndrome. Exceptional Children 1983; 49: 5, 449-550.

${ }^{4}$ Collman RD, Stoller A. Data on mongolism in Victoria, Australia. Prevalence and life expectation. J Ment Def Res 1963; 7: 60.

${ }^{5}$ Collman RD, Stoller A. Comparison of age distribution for mothers of mongols born in high and low incidence areas and years in Victoria (1942-57). J Ment Def Res 1963; 7: 79.

${ }^{6}$ Balarajan R, Donnan SPB, Adelstein AM. Mortality and cause of death in Down's Syndrome. J Epidemiol Community Health 1982; 36: 127-9.

${ }^{7}$ Elwood JH, Darragh PM. Prevalence of mongolism in Northern Ireland. J Ment Def Res 1981; 25: 157-60.

${ }^{8}$ Juberg RC, Goshen CR, Sholte FG. Socioeconomic characteristics of the parents of patients with the G1-trisomy syndrome. Social Biology 1973; 20: 404.

${ }^{9}$ Carr J. The effect of the severely subnormal on their families. In: Clarke ADB, Clarke AM. Mental deficiency. Methuen, 1974.

${ }^{10}$ Carr J. Young children with Down's syndrome. Butterworth, 1975.

${ }^{11}$ Gath A. Down's Syndrome and the family. Academic Press, 1978.

${ }^{12}$ OPCS (1976) Birth statistics, England and Wales, Series FM1, No. 3, (1982) Congential Malformations and Parents' occupations, MB382/1.

${ }^{13}$ Griffiths AJF, Lowry RB, Renwick DHG. Down's $0 \omega$ syndrome and maternal age in British Columbia.O Environmental Health Prospectives 1979; 31: 9-11.

${ }^{14}$ Pearce $D$, Britton $M$. The decline in births: some $\frac{\rho}{\supset}$ socio-economic aspects. Population Trends 1977; 7:冗 OPCS.

${ }^{15}$ Dunnell K. Family formation in 1976. OPCS, 1979.

${ }^{16}$ Shepperdson B. Mongol children and their familyo background in South Wales. Postgraduate thesis University College of Swansea, 1976. 